\title{
The Diversification of Teaching Pattern for the Landscape Design Research
}

\author{
Huiping Zhang \\ Department of Environmental Art Design, Hebei Institute of Fine Art ,ShiJiaZhuang HeBei, 050700, \\ China
}

Keywords: landscape design teaching mode, diversification

\begin{abstract}
After exploration research in domestic institutions, landscape design course has development, and it has gradually become one of the important basic course of environmental art major. In order to better meet the social demand for landscape design talent, and better enrich landscape professional was perfected in China, the paper according to the complete landscape design Routine teaching context such as landscape design course teaching goal, teaching subject, teaching methods and course evaluation, in order to establish a new diversified teaching pattern of the landscape design research.
\end{abstract}

\section{Introduction}

In recent years, along with the rapid development of domestic landscape design industry for landscape design talents demand increased rapidly, which prompted the landscape design specialty in universities and colleges. in domestic environmental art design industry is growing in the position. Although after years of exploration and accumulation, the domestic landscape design professional education has made some achievements, but relative to the social demand and discipline their own development demand, it is not yet mature.

Landscape design is a comprehensive knowledge structure stronger industries, "landscape is not the same as other disciplines, it is the intersection of multiple disciplines, both in the west, or in China, is beautiful but difficult to say." Therefore, landscape design education needs to have a more diversified teaching model as a support, to the comprehensive knowledge structure is more effective to teach, and make the way to teach more flexible, diverse, teaching content more rich and practical.

\section{Profile, the Current Domestic Landscape Design Course Teaching Mode}

At present, the domestic landscape design course is mainly for the institutions of higher learning of art and design, city planning, architecture and landscape gardening professional set up, and gradually become the environmental art design major in a professional required course. Landscape design course belongs to the liberal arts and science overlapping specialized courses Cheng, complex and strong professional knowledge structure.

Although in landscape design course teaching exploration in recent years, has been a part of the landscape design course teaching methods are discussed in the article, and summarizes a lot of valuable experience, but due to a late start, for this relatively young professional class, there are mainly two aspects: one side, the whole teaching pattern of landscape design inevitably affected by other subjects of traditional teaching mode Single and slightly, difficult to adapt to the social demand for landscape design talents; On the other hand, in each teaching link is also insufficient

Environment art students from arts college entrance examination enrollment, major landscape in relative to the student, has the stronger ability of art creativity and graphic expression, but its deviation in science and engineering knowledge, understanding of space and design ability is relatively weak. For a long time, environment arts professional works of many students have heavy performance characteristics of light content, emphasized the beautiful form in the process of design is novel, but seldom consider the most basic function, so can only be of good draftsman and can't be a good designer. To this, many students also feel confused, oneself use four years through college courses, found work may and vocational technical secondary school graduates, even on the use of 
drawing software proficiency is worse than the latter. Relative to the cultivation of higher vocational colleges and universities career guidance, technical secondary school at the university of education on the quality and ability training as the guide, for environment arts major, which is to cultivate students ability of design quality and design thinking.

In the unit teaching, landscape design class is usually in a professional basic course and interior design class before. Students through a series of interior space and the corresponding design practice, has formed relatively strong interior space, microscopic and meticulous way of thinking, and the use of perspective for the design of the visual expression way. Into the landscape design course, want to shift to more large-scale outdoor space design, especially in relatively more abstract plan for designing idea and expression, difficult to adapt to, on the scale of space form and spatial ability is weak, need to try to guide teachers consciously, make its sense and measure concept gradually formed outdoor places.

Such Disciplines as Geography, Land Resources of the Cross. Relying on the basic concepts of landscape ecology, the basic theory and research methods, absorb the essence of geographical science, to landscape as the research object, the landscape spatial pattern, function and the relationships between research and time variation of lateral changes and the longitudinal study, the combination of landscape pattern optimization configuration and planning through the teaching emphasis to master basic concept and basic principle of landscape ecology, landscape structure change of driving factors analysis of landscape ecological planning and design of the practical application, landscape ecology and the relationship between sustainable land use, etc., [1] in geography, resources and environment, for the future work in the field of land planning, etc. Such as Beijing normal university, land resource management specialty and geographical sciences, fujian normal university geography education specialty and land planning, resources and environment of fujian agriculture and forestry university and the urban and rural planning management and so on.

With Subjects Such as Agriculture, Forestry and Environmental Studies. Landscape ecology as a solution to the current resources and environment, effective discipline, the problems of the biodiversity protection in the development and utilization of resources, urban development planning, land use planning and environmental protection plays an important role, using research methods of landscape ecology, such as composite population theory, seepage theory and scale theory, fragmentation geometry theory and the relationship between landscape process and landscape function is a good way to explain all phenomena of the landscape on different scales, and the key to find the problem, in order to establish the sustainable development of agriculture, forestry mode for reference, and in the service of environmental assessment, environmental protection and reasonable and effective utilization of resources, and many other aspects. Such as anhui normal university of agriculture and the environment ecology of ecological engineering, guangxi university, central university for nationalities ecology specialty, fujian agriculture and forestry university of forestry and ecology.

Such Disciplines as Landscape Architecture, Landscape Planning of the Cross. Belongs to the category of spatial ecology, landscape ecology is the study of composite law of ecological systems in space, become the important theoretical support of landscape planning and design. Through the study of landscape ecology can make students to master relevant knowledge and theory, on the basis of cultivating ecological consciousness and the concept of sustainable development of landscape planning and design talent, the master of landscape classification, space combination, methods of optimal allocation, training in urban and rural landscape planning, landscape architecture, landscape engineering design and other aspects of professionalism. Such as tongji university professional landscape architecture and landscape planning and tourism management specialty of landscape architecture, yunnan university, zhejiang university of agriculture, forestry and landscape engineering specialty and garden planning and design, etc.

Cross and Biological Sciences and Biotechnology Subject. To landscape as a basic scale, research on the landscape spatial pattern, the structure and function change and migration, the relationship between the material flow and energy circulation. Landscape pattern changes tend to affect the all kinds of ecological process, such as regional microclimate, soil nutrient flow and 
erosion, biological migration, soil erosion, etc. therefore, through the study of landscape ecology will provide biological science and biological technology subject with new theory and method, to seek better biological conservation. Such as Beijing normal university, college of life science of biotechnology and biological sciences.

Management, Tourism and other Disciplines. Landscape ecology in ecological protection and recreation resource management, planning management occupies an important position, resources and environment and urban and rural planning and management, tourism management students learn to master the landscape ecology in landscape planning, land use, the application of tourism development, etc, [2] make its ideas and methods in study of landscape scale and public management subject unifies, to solve practical problems, and make decisions. Such as the resources and environment of fujian agriculture and forestry university and the urban and rural planning management and forest resources protection and recreation of professional, guizhou university professional forest resource protection and tourism scenic spot management, zhejiang forestry university and tongji university professional tourism management, etc.

\section{The Specific Problems of the Current Domestic Landscape Design Course Teaching}

The teaching goals are not clear Due to the nature of the landscape design course has a multi-disciplinary overlapping, therefore, the domestic various colleges and universities on the basis of resource sharing advantages make full use of campus, the use of the existing related professional in different orientation to landscape design course curriculum. If placed in agronomy in the landscape design course, in which usually add more botanical knowledge; Placed under civil engineering professional landscape design class Cheng, usually join in the curriculum of civil engineering knowledge; And placed in the professional art of landscape design course, are usually more strengthen the knowledge content of art design class, etc.

The education way, combined with its own resources development landscape design in the landscape design education get diversified overall comprehensive development at the same time, also make landscape design course teaching goal becomes fuzzy not clear, and then for the landscape design of the teaching have brought many new problems. As in teaching how to find the equilibrium and balance the related discipline knowledge, avoid the barycenter offset of the course content; In the integration phase close subject knowledge make them supplement each other, how to adopt appropriate teaching methods, etc., will be a breakthrough point of teaching reform research.

The teaching subject simplification In social practice, the content of the landscape design has a wide range, including residential area landscape design, square landscape design, urban park landscape design, the street landscape design, and other types. However, in the domestic landscape design of the teaching subject, often hard to make a choice, the various types of landscape design task and can only be one or two types of them to make specific training. This relatively single topic selection mode of teaching, to cultivate comprehensive and high quality practical type, landscape design talent, hard to do better meet the social demand for landscape design talent.

The teaching method of simplifying assumptions At present, the domestic landscape design of the course is usually adopt the teaching methods of theory + design practice, for the landscape design of the relatively strong practical work, this kind of teaching method is too single, for many students real actual content is difficult to grasp. Such as various types of landscape space scale and the scale of the landscape space in difficult to accurately; Suffering of landscape space in the sense of reality In order to achieve real; On the landscape design of artificial environment color in photograph reflect with light color changes Difficult to intuitive feelings.

Check method simplification course assessment is one of the effective means of inspection course learning, is an important part in the teaching, but in the current domestic landscape design course examination way, basic limitations in due course design assignments this is relatively single traditional way. Due to the landscape design course with strong practicality and knowledge content of cross particularity, the single way of examination can not comprehensive, integrated, in-depth investigation of students learning the course of real and effective results. 


\section{The "Trinity" of the Teaching Goal}

Landscape design course is a practical design course, design process is a from function to form, and from form to function more stages of creative thinking activity, through vision, planning, implementation and production process. [3] Landscape design, therefore, the teaching goal of the course include at least the following three kinds of ability, thinking ability, research ability and design ability to express the three complement each other, be short of one cannot.

Design Thinking Ability. Environmental art professional to develop the students' ability of thinking in design, landscape design as one of the important courses, more emphasis on the design thinking ability of students, to guide the student to carry on the viewing Angle and directional thinking, to find and try to solve the problem of various methods. Design, however, the cultivation of thinking ability is a long and gradual process, can't be through theoretical teaching and the students to master, can only be guided in the process of design practice, this requires teachers to communicate with students, to discuss ways to guide students to think deeply and active innovation.

Research and Analysis Ability. Landscape design is a beautify the problem not only, more is a combination of technology and art courses, therefore, the landscape design course teaching should also pay attention to the combination of art and science and technology knowledge, with emphasis on the design thinking and cultivate students creative rational research and analysis ability. In the teaching, the cultivation of the ability of students to design and analysis can be done through do more scheme evaluation. For design students, pointed out its problems existing in the design of, encourage students themselves to find solution to find information. In addition, social investigation in the design courses, is also a important way to cultivate students' ability to research and analysis. According to the selected topic, organizes the student to give you into urban social investigation, on the basis of further research, understand the landscape and architecture, landscape and city, the relationship between landscape and environment, to cultivate students found the problem, the ability to analyze and solve problems.

Design Skills. Design expression ability mainly includes the hand-painted performance ability, ability to computer aided performance, model making, performance skills and language ability. With good communication skills, design thinking to intuitively physical and chemical performance, so as to be understanding and interpretation. Good communication skills, in turn, can also help inspire, train the ability of design thinking. Environment arts students already has the characteristics of high artistic accomplishment, modeling ability, the design expression occupies a certain advantage, but should avoid engineering drawing is not rigorous, practicality is not strong. Language power of expression will be simulated to design report and organize groups to discuss ways to develop.

The Micro-scale Topic of Teaching. In terms of selected topic and content, the landscape design of environmental art specialty course should be different from the landscape disciplines of professional courses, in the micro sense, medium and small scale landscape design content as the main object of teaching practice, such as garden design, square and residential area landscape design, etc. Some scholars put forward the concept of "visual landscape design", [4]i.e., according to people's heads up and walk for metrics, with man's sensory experience especially visual sensory experiences as the main basis for the design. The author thinks that, in the design of its emphasis on the characteristics of creativity and visual impact of the works, the advantage of suits in environment arts students, and also social needs and expectations about the environment art graduates are consistent, should be as environmental art professional landscape design teaching.

Even the landscape design of micro scale, is also a complex design process, it is difficult to make through a design task in teaching students to understand the landscape design of many types. Therefore, the landscape design course can be subdivided into two topics: the city square landscape design and the residential area landscape design. The two types is the most basic type of landscape design, which is the most common design project, students through the study of the two design which can understand the general methods and steps of landscape design, and understand the characteristics of different landscape types. 


\section{A variety of Teaching Methods}

Case Teaching Method. Before the subject design, introduce the knowledge of the subject design and method, help students understand the purpose of the study design, to design better. But in terms of art students, the study of the theory of pure is difficult to understand and not used. Application of case teaching method can turn a boring theory knowledge pertaining to the design case, through the case of interpretation and evaluation, deepen students' understanding of theoretical knowledge and memory, and to cultivate and improve the students' thinking in images.

As used in the case of teaching, to have certain representativeness and authenticity, reflect the content and forms of knowledge, can be a master of classical works, also can be a teacher myself involved in the practice project, the former has certain representativeness, can improve the students' design vision; Because the latter is a teacher's personal practice, to the project background and more detailed introduction of the design process.

It is important to note that the student for a master and classic case tend to have worship complex, teachers can not only the interpretation of total floor plan and rendering is a simple introduction and vague praise, should be through a series of analysis and design sketch, and a detailed description of the design process, to guide students from the aspects of function, structure, and art forms such as in-depth analysis and design, and rationally understand design where in the hell, where there is regret, and how to study masters of design thinking and design methods, training students the spirit of design research.

In addition, if conditional, organizes the student to an on-the-spot investigation of cases, you can let the students have a more vivid and comprehensive feel.

The Heuristic Teaching. Heuristic teaching mainly discuss teaching methods, promoting between students, teachers and students interaction and communication, has been shown to play a more conducive to students' initiative, using this method in design course. Change the habits of students passively waiting for the teacher to change figure, organize and launch a discussion, guide students take the initiative to explain their plan, other students some questions and published their own point of view, teachers guide series, the teaching method one can find problems of students in learning and understanding, second can cultivate the students' ability to analyze and solve problems, at the same time also can improve the students' ability of expression.

Simulation Teaching Method. Landscape design is a complex integrated design process, including the design of a variety of factors to consider and balance of interests, builders, different users and designers position, focus on the content and also each are not identical, to the requirement of design in general, only through the interpretation of teachers, students consider in an all-round way and it is hard to balance. By role playing, simulation teaching method can make students more image understanding that may exist in the design of each game, and their common needs and different requirements for design, the debate between different roles can also help students to clear the factors must be considered in the design of and need to solve the problem, and can classify them according to how important they are and trade-offs, to get more suitable solutions. This way of teaching the complex relationships and intuitive show in front of the students, lively and interesting, and is conducive to enhance the students' learning initiative, make students learn more flexible, grasp firmly.

\section{The Diversification of Teaching Pattern of the Landscape Design Research}

Landscape design course of explicit teaching objects, teaching contents, diversified landscape design course based on their special properties will be located in the teaching goal of "knowledge structure diversification, diversification of actual combat skills training high quality, comprehensive landscape design class talent", only made clear the goal. To meet the needs of today's society to landscape design class talented person standard, at the same time, it puts forward higher requirements to the teaching content. Landscape design is the integration of liberal arts and science, knowledge in range is relatively wide, including literature, history, geography, architecture, engineering, etc., and focused on the cross complementary knowledge. Because of this, 
on the premise of clear teaching goal, on the one hand, to further enrich the teaching contents in landscape design; On the other hand, should be fully coordinated various related disciplines fusion in the landscape design course The proportion of occupied with each other, for example, in the landscape design course should be fully embody botany, landscape design and landscape architecture, garden horticulture, the combination of related subjects such as history, literature, knowledge structure, at the same time the landscape design of the original algorithm, methods, steps and the elements of landscape design analysis and so on course content should be dominant, and the natural elements in the landscape design elements should be fully combined with geography, botany, landscape garden horticulture knowledge such as teaching, in the artificial elements in landscape design elements, should be fully combined with the teaching of knowledge of history, culture, architecture and so on. Through the landscape design course teaching content is diverse patterns of way, make the concept of landscape design education towards its teaching goal step by step.

The landscape design course topic selection should pay attention to the diversification of teaching. Combined with social demand for landscape design talents standards and clear teaching goal, in the landscape design course teaching should adhere to the multi-level, multi-angle, from the overall to the diversity of specific teaching topic selection model. Teaching topic selection should be based on the overall framework, the various types of landscape design subject in-depth, specifically, form the multi-level teaching topic selection model. Teaching topic, for example, square landscape design can be according to the different classification of square type separately; Strip of space landscape design teaching topics from road landscape design and shore water landscape design two aspects; Teaching subject of city park landscape design can be divided into comprehensive park landscape design, landscape design, children's park forest park landscape design, the botanical garden landscape design and landscape design in the zoo.

The landscape design course of diversified teaching method. In view of the present domestic are more traditional, relatively single "theory + design" teaching method, the landscape design teaching methods can be from "theory + practice + experiment and actual combat" diversified aspects simultaneously.

The Theory Teaching of Teaching Methods. Through the theoretical study to make the students to the general situation of landscape design both at home and abroad have a preliminary understanding. On the one hand, through the appreciation of good landscape design works at home and abroad, make the students to broaden their; On the other hand, causes the student to fully understand the connotation of landscape design and its social value, at the same time, a solid grasp of scientific and reasonable landscape design principles, methods, steps, etc.

The Field Practice Teaching. Encourage and guide students to the field practice, landscape construction field make a combination of theory knowledge and practice in teaching, makes theoretical knowledge practice good guidance, but also make practice of theoretical knowledge digestion, absorption, the best way. [5] In the process, make the students understand the formation process of good landscape and how it is gradually perfect and mature. As "people is the main part of the cognitive object, the object is the object of cognition, and cognition is the main body of the object in the scene gradually sublimation process of aesthetic and appreciation." at the same time, it is also fully respect the student in the teaching of cognitive structure of the teaching experiment.

Courses Experimental Teaching Method. Experiment is aimed at diversification of landscape design course topics, produce various types of landscape design model, in the process of making model for on-the-spot practice interlinked with true feelings, feelings, feelings of landscape environment in space scale of psychological demand, etc.

The Actual Teaching Practice. Through practical exercises, students will study landscape design course in the first three parts absorb by the integrated use of knowledge, strengthen students' understanding of the theoretical part and the theoretical knowledge in practice the ability to use flexibly, and stimulate students in the process on the basis of respect for local culture innovation thinking.

The Assessment Mode Diversification of Landscape Design Course. For some traditional subjects, the assessment methods of usually the adoption of a single way of theory or experiment of 
examination, to achieve comprehensive evaluation criteria of landscape design, the traditional curriculum evaluation methods have some shortcomings.

Landscape design is a practical stronger course, theory to guide practice, practice and promote the development of the theory. Therefore, students must be good at the same time the landscape design course theory accomplishment and strong ability of practical design, so the landscape design course appraisal to student's theoretical accomplishment, design production ability and practice ability of comprehensive assessment such as multiple directions. Examination of the specific ways to reference on the whole landscape case gave students a complete set of design, but specific to conduct a comprehensive investigation from the following three aspects:

Theoretical Examination. Asked the students according to their own design with a certain length limit of design specification (may limit the length limit of 3000 words or so), or to complete a course paper design. Through the theoretical part of the assessment, can a comprehensive and in-depth investigation plan for middle school students own design ideas and design concept.

The Production Ability of the Inspection. Asked the students according to their own design make landscape model according to certain proportion. In model can fully examining the students of space scale, scale coordination control ability and the landscape environment of artistic processing ability and so on. Should be reflected as real as possible model making landscape design content.

Design Scheme Evaluation. Students are required to make a certain level of a full set of landscape design, including the layout, traffic plan and landscape plant plan, construction drawing, rendering and a series of complete schemes, and bound into the text. Through the appraisal of design scheme can comprehensive investigation the student to the course learning result and performance ability of solution.

Landscape design of the curriculum evaluation in combining the above three evaluation at the same time, should also be determined according to the design to the difficulty of the questions by the students a single complete or group cooperation. In way of grading, considering actively encourage students comprehensive cultivation of his landscape design literacy in normal times, you can refer to the final assessment result as worth $60 \%$ of the usual performance scores account for $40 \%$ of the total grade. Through such score way, causes the student to weaken the traditional concept of one-sided attention to score in the exam, turned its attention to daily to the cultivation of their comprehensive design literacy, the purpose is to strengthen the establishment of the knowledge accumulation and encouraging innovative thinking mode.

\section{Conclusion}

This article from the current domestic exploration on the general situation of the teaching mode, the landscape design course, from the current domestic landscape design problems existing in the teaching of specific analysis, from establishing the diversified teaching pattern of the landscape design of a new intensive research, aims to explore a more suitable for social development needs, is more advantageous to develop students for landscape design of the innovative teaching mode of thinking, after training with comprehensive quality and practice ability of landscape design talent, and further promote, China's landscape design industry and the development of landscape architecture education. About the reform of teaching, the author put them into teaching practice, practice test these ideas are effective, improve the students' professional skills. Due to the closer to the actual course content more concise, method of teaching students more easy to accept; Practice project combined with the multimedia teaching, and the case analysis, targeted follow the market development, cooperate with landscape practice, improved the students' learning enthusiasm, also added a employment channels. Of course, these measures still need to improve, the exploration of teaching reform, at the same time, also make the cultivation of the students in a diverse landscape design in course teaching pattern, landscape and landscape aesthetic appreciation ability to improve, eyes open, eventually create a good landscape design works with a strong taste of new era. 


\section{References}

[1] Pan Wu-hua. Indoor display art design. Beijing, China Building Industry Press, 1999

[2] Yan Wen-Ming. Modern indoor display art is analysed and the relationship between the people

[J]. China Science and Technology Expo 2009 (14)

[3] Zhang Wei-wei. Display is analysed the meaning of art in the indoor environment [J]. New Finance and Economics (theory), 2010 (6)

[4] Cheng Kun. Environmental art design professional practicality teaching exploration [J]. Information Science and Technology, 2009 (10) : 732

[5] Ma Rui-dong. The scientific environmental art teaching in colleges and universities study [J]. Philosophy and the Humanities, 2009 (8) 